\title{
Application of task-based teaching mode in college English teaching
}

\author{
Zhao Hui-Min ${ }^{1, a}$ \\ ${ }^{1}$ Teaching and Research Institute of Foreign Languages, Bohai University, Jinzhou 121013, China \\ aemail: hmzhao2008@163.com
}

Keywords: Constructivism, Task-based language teaching, English ability.

\begin{abstract}
The economic and social developments put forward higher requirements for English personnel. Currently, college English teaching still remains in traditional teaching mode and students' English comprehensive application ability is still low and they can not meet the demands of the workplace. By constructivism theory, the author investigates the application of task-based teaching mode in college English teaching and proposes the concrete strategies on the corresponding teaching method.
\end{abstract}

\section{Introduction}

With the development of society and economy, the social demand for English personnel is more and more high. The needs of job for English personnel transform from knowledge to competence, which requires the English personnel to have higher listening, speaking, reading and writing abilities. Currently, college English teaching still remains in traditional teaching mode. It has caused many problems for college students, such as weariness of English learning, low learning enthusiasm and low efficiency of English learning. Although the traditional English teaching mode has many drawbacks, an effective English teaching mode is still absent. It has become the focus of English teaching reform that a new teaching mode must be found to improve the college students' English comprehensive ability and get rid of the rigid situation of English teaching and improve the students' interest in English learning as well as the autonomous learning ability. Fortunately, based on constructivism, task-based teaching mode can improve the efficiency of English teaching as well as the students' learning enthusiasm and initiative, so as to improve the students' English comprehensive ability. In this article, the author investigates to apply the task-based teaching mode to college English teaching in order to explore the appropriate teaching methods.

\section{Constructivism and task-based language teaching}

Constructivism originates from children's cognitive development theory and its main representative is Piaget.[1] Constructivism holds that knowledge is not achieved by teaching but obtained in a certain situation with social and cultural background and the learner is helped by others and uses the necessary learning materials to construct the meaning initiatively. Because learning is performed in a certain situation with social and cultural background, in which the learner is helped by others, the learning environment consists of four factors, i.e. situation, cooperation, conversation and meaning construction. Constructivism advocates that learning should be student-centered and under the guidance of teacher. That is, it not only emphasizes the cognitive role of students, but also recognizes the guidance of teacher. The teacher is the helper and facilitator of meaning construction rather than the provider of knowledge. Students are the main body of information processing and the active constructor of meaning rather than passive recipients of external stimuli and the indoctrinated subject. Constructivism theory can better explain the cognitive rules of learning process. That is, it can explain how learning takes place and meaning is constructed and the concept is formed as well as what main factors the ideal learning environment should include.

When the students become the active constructor of meaning, they should play the role of main body in the following aspects.[2] (1) Heuristic method should be used to construct the meaning of knowledge for students. (2) Students should actively collect and analyze the information and 
materials in the meaning construction process and propose series of hypothesis and try to verify them. (3) Students should connect the knowledge they have with the knowledge they are learning. Connecting and thinking are the keys of meaning construction. If the process of connecting and thinking is combined with the consultation process in collaborative learning, the students can more efficiently construct the meaning of knowledge and therefore, the learning effect will be much better. Consultation includes self-consultation and mutual consultation. Self-consultation means that one argues about the questions with himself. Mutual-consultation means that students discuss and debate in groups. Based on the above analysis, we believe that the task-based teaching method can be adopted to construct the knowledge structure for students, so as to stimulate the enthusiasm of students.

Task-based language teaching means that the teacher guides the students to complete the task of teaching in class for language learning. It is the language teaching method emerging in the 1980s that emphasizes learning by doing. It is the developing result of communicative teaching method and has attracted the attention of researchers widely in language education field. The theory holds that the mastery of language is not the consequence of language training and learning, but the consequence of using language in communicating activities. In teaching, the teacher should design the specific and operative tasks based on certain communication and language project. Students should complete the learning tasks through the language activities such as expression, communication, negotiation, inquiry, interpretation and consultation, so as to learn and master the language. Task-based teaching method is formed by absorbing the advantages of various teaching methods and it does not exclude other teaching methods.

Tasked-based teaching method is student-centered and it mainly focuses on the fields of cognition and psychological linguistics. It provides the training opportunity to students through the class language activities and opening communicative tasks. The class activities consist of series of teaching tasks. In the implementation process, the learners pay attention to language communication, make full use of the target language and communicate to obtain information to complete the tasks. The learning process is along an open approach to achieve the goal of teaching.

Task-based language teaching can stimulate the learning motivation of students maximally. Due to the clear and specific objectives of curriculum and task, students try to complete the tasks by using the language. Students no longer passively learn the knowledge with the teacher's instruction. They have more opportunities to choose the topics that they are interested in, express their ideas and describe what they are familiar with, choose the materials that they like and construct their own knowledge structures. In the process of completing the tasks, students have the opportunities to experience success, and know their own shortcomings. Students can learn to adjust their learning goals and adjust their learning behaviors and gradually cultivate the autonomous learning consciousness.[3]

\section{Characteristics of task-based teaching}

In the task-based teaching, the teacher designs the actual teaching activities according to the overall goal of curriculum and teaching content and attracts the students to participate actively in the activities. The students learn and use English to complete the task of learning through thinking, investigation, discussion, communication and cooperation. In the task-based teaching, teacher should deal with the following aspects.[4]

(i)Set reasonable teaching goal. Reasonable teaching goal is the key of task-based teaching. Teacher should know the English learning levels of students and sets the appropriate teaching goals for students according to their learning levels, such as the realization of grammar learning and oral practice etc. Too high or too low learning goals are not appropriate. The class organization of teaching task must be focused on the teaching objectives. Each task is designed to achieve a certain teaching objective. The difficulty of learning task should be moderate so that the students can successfully complete the tasks. In English teaching, the teacher should pay more attention to improve the students' use of English in accuracy, fluency and complexity. In the classroom teaching, the teacher should not only emphasize the individual grammatical structure, but also focuses on the comprehensive discourse ability. The teacher organizes the fixed phrases and expressions for 
students in advance, and encourages the students to use these fixed usage in the completion of tasks, so as to achieve the purpose of successful communication.

(ii) Position the learning tasks definitely. Teacher should make the students understand why these tasks are arranged in classroom teaching, and make the students aware of the importance of their tasks for developing the language ability. Otherwise, the students do not understand the purpose of completing these tasks and they will not devote to the practice of language point effectively. Therefore, the teacher should not be ambiguous in the design of teaching tasks. The teaching tasks should be divided in detail and the discussion results should be definitely asked. This specifies the tasks for the students and prevents them to do the tasks carelessly. For example, during the teaching of pollution, if the teacher said: "Now, let's talk about the pollution in groups", the students would simply discuss the question carelessly. The learning task is not well done. If the teacher asked the students to list at least three kinds of pollution as well as the corresponding countermeasures, the effect of group discussion will greatly be enhanced.

(iii) Provide the students with language training opportunities and ensure that the students actively participate in the activities. The key point of task-based teaching is the active participation of students. The teacher should ensure that each of the students actively participate in the learning activities. Therefore, the teacher should make sure that these tasks are true and close to the daily life of students and are interesting to carry out discussion. Secondly, the tasks designed by the teacher should not be too easy, and they should be exploratory so that the students are interested in discussion. The best tasks are those that can fully stimulate the students' arguments and make them express their ideas freely. Moreover, the teacher should provide the students with the opportunity to focus on the language forms. That is, the students can pay attention to their own language expression in group discussion and personal speech so as to make correction continuously.

(iv) Evaluation and self-evaluation for the language ability of students. Evaluation of language ability is a direct way to test the language ability of students. It is the measurement that evaluates the language ability of students through listening, speaking, reading, writing and translation. It requires the students to use the learned knowledge to complete the various tasks. By completing these tasks, the language abilities of students are evaluated. These evaluating tasks include listening and simultaneously writing, listening and filling in the blanks, direct writing, spoken dialogue or reading and choosing the correct answers. Self-evaluation is the self-learning or actively learning strategy to give full play to students' subjective initiative. Self-evaluation is the necessary complement to the measurement relying on teachers to evaluate the learning effect of students. It can fully play the role of main body for the students, makes the students learn and evaluate by themselves. This can help them to find the problems in learning so as to achieve the purpose of self-correcting. Most importantly, the students experience the growth process of making mistakes-correcting-progressing. This is the way that must be passed during self-progressing.

\section{Strategies of task-based teaching in college English teaching}

According to the classroom teaching mode of Willis, college task-based English teaching can be divided into three stages. [5] The teaching process can be listed as follows. The teacher first raises the new topic and introduces the new vocabulary and phrases to the students. Then the teacher assigns the tasks to the students and asks the students to complete the tasks in groups. During the group activities, the teacher should pay attention to the situation of students and provide some suggestions for those students who need help. Then the representative of each group reports the results of the group discussion to the whole class. In the stage of language focus, the teacher summarizes the language knowledge points to the students.

(i)Pre-task. In this stage, the teacher introduces the topic to the students and asks the students to prepare for the tasks. Its main purpose is to highlight the theme of the tasks and activate the related knowledge, reduce the students' knowledge processing load, and provide useful input for students. When performing the task-based teaching, the teacher presents the according language materials to the students as follows. (1) Play the video related to the tasks for students and ask them to observe the task mode. (2) Ask the students to complete the simple activities related to the tasks and activate their 
original cognitive schema. (3) Provide enough time to the students for the tasks. After the preparation, the students can master the overall requirement of tasks and complete the tasks by using more accurate, complex and coherent language. In this process, the teacher explores the topic together with the students, introduces useful words and expressions to students and helps them to understand the task instructions.

(ii)Task-cycle. It includes task activities, plans and reports. In this stage, the students complete the tasks in groups. The teacher gives some guidance to the students and encourages them to report their completion of tasks via oral or written form. Finally, the representatives of groups report their results to the whole class so that they exchange the results with others. The group activities have the advantages that the language output of students increases significantly. In group activities, students can change their language behaviors and have more opportunities of using language from different perspectives. In group activities, the teacher has more opportunities for individual guidance and at the same time it can reduce the anxiety of students. This teaching method provides the students with more opportunities of applying language and encourages the students to use formal language as well as the oral and written language. It is noticed that the task instructions is very important to the students in this stage. If the teacher gives the instructions too cursorily and ambiguously, most students have no idea of what they should do and thus the task can not be well done. Therefore, the instruction of tasks should be clear in the following aspects. It must have definite objectives and requirements and clearly describes the purpose of task and the requirements of the tasks. The tasks should be assigned to the students definitely. For instance, the representative of group should be designated and each student should have his specific task in group activities. Only the students are definitely assigned the tasks, will they seriously participate in the tasks.

(iii)Language focus. It includes the interpretation and practice. In this stage, the students have contacted the language as a whole and have processed the language from cognition, and they also have grasped the common meaning of language. In this stage, some special form of language is emphasized. The teacher helps students to explore the language and improve the usage of syntax, vocabulary and phrases. In this stage, students systemize the language features that they have learned and the teacher emphasizes these language forms again to attract the attention of students so as to reinforce these language points. In this stage, the teacher concludes the points of language knowledge and students are easier to accept the teaching procedures in this stage.

The three stages are the general steps of task-based teaching, in which the task-ring determines the whole effect of teaching process. Note that, due to the large amount of students in class, it is hard for English teacher to ask all the students to speak and practice the language. Therefore, if possible, group activities should be carried out in the task-ring stage. For example, in listening and reading class, after the students listen to a paragraph or interpretation, the teacher asks the students to think and communicate with others through series of questions. Then the teacher checks the discussion results of students by communicating with them. The questions of introduction can stimulate the students' interest and thinking on the topic. The question of the main part can make the students organize the discussions. The questions of the conclusion can check the understanding of students and also can make a summary and conclusion. For the students having strong language ability, the teacher can also design a variety of simulating tasks and provide the communication environment close to real life. Students can play different roles in the communication and fully perform their language ability. Moreover, the task can be carried out via the forms of debate, extempore and story solitaire. These group activities can make the students learn by doing and cultivate the students' comprehensive ability of language.

\section{Summary}

The traditional teaching mode has many problems in the cultivation of students' language ability. Based on constructivism, the task-based teaching can effectively stimulate the enthusiasm of students and realize the active construction of language knowledge. This teaching mode is student-centered, and at the same time it pays attention to the guidance of teacher and emphasizes the construction of knowledge through active learning. In class, the teacher designs a series of learning tasks based on the 
teaching objectives, and asks the students to complete these tasks so as to master the language knowledge and enhance the language comprehensive ability.

\section{Acknowledgement}

This work is part of the project of Research on Task-based English Teaching Mode Based on Constructivism Theory. The work has been supported from the fund of Liaoning Provincial Federation Social Science Circles (No. 2015lslktziwx-03), and also from the fund of Liaoning Planning Office of Philosophy and Social Sciences (L13CYY018).

\section{References}

[1] J. Piaget, The Origins of Intelligence in Children. New York: International Universities Press (1966).

[2] D. Nunan, Communicative tasks and the language curriculum. TESOL Quarterly 25 (1991) 279-295.

[3] R. Ellis, Task-based research and language pedagogy, Language Teaching Research, 4 (2000) 193-220.

[4] R. Ellis, Task-Based Language Learning and Teaching. Oxford: Oxford University Press (2003).

[5] J. Willis, A Framework for Task-Based Learning. London: Longman (1996). 